Aims To provide an overview of the application of SDM in people with ID in the palliative care phase.

Methods In this scoping review, we systematically searched in the Embase, Medline and PsychINFO databases for studies that evaluated the SDM process in people with ID in the palliative phase.

Results Of 402 titles and abstracts, 14 full studies were included. 10 were empirical studies, 3 were opinion papers and 1 was a legal report. Papers show an increasing focus on the importance of involvement of people with ID themselves, or - if applicable - their loved ones, in making medical decisions around the end of their lives. None of the papers described SDM in the palliative care phase, and no best practices, guidelines or definitions were shown for SDM in the palliative care phase.

Conclusion This study shows that there is no consensus-based model about what SDM regarding people with an ID should look like. General recommendations indicate that we should involve people with an ID more in the decision-making process by providing them an appropriate environment full of support.

\section{OP44 'LIKE PEARLS ON A STRING': DEVELOPING A PEDIATRIC ADVANCE CARE PLANNING INTERVENTION WITH A STEP-BY-STEP MODULAR DESIGN}

${ }^{1} \mathrm{~K}$ Hein*, ${ }^{1} \mathrm{~K}$ Knochel, ${ }^{1} \mathrm{~V}$ Zaimovic, ${ }^{1} \mathrm{D}$ Reimann, ${ }^{2} \mathrm{GD}$ Borasio, ${ }^{1} \mathrm{M}$ Führer. ${ }^{1}$ University Children's Hospital Munich, MUNICH, Germany; ${ }^{2}$ Centre Hospitalier Universitaire Vaudois, LAUSANNE, Switzerland

\subsection{6/spcare-2019-ACPICONGRESSABS.44}

Background Advance care planning concepts for adults are not directly applicable to the pediatric setting. Aim of the study was to develop a specific pediatric advance care planning (pACP) intervention using a participatory approach.

Methods Bereaved parents and healthcare professionals selected by purposeful sampling participated in two transdisciplinary workshops. In the first workshop, discussion groups identified key elements of pACP. In the second, participants organized the key elements and visualized the pACP process on a timeline. Results were systematized, translated into a modular program, and sent back to participants for validation.

Results The structured intervention organizes pACP elements in a modular design. First steps include 1) Preparation: building up trustful relationships; 2) Opening discussions: framing the process, making participants' expectations and aims explicit.

The next modules can be arranged in accordance with participants' priorities: 3) Focusing on the child: quality of life, wishes and hopes; 4) Medical topics: emergency situations and disease-specific crises discussed in hypothetical scenarios; 5) End of life issues: optional.

Final steps 6) Concluding discussions: validation of written documents (e.g. parental advance directives), discussion on their implementation; 7) Implementation: informing all relevant stakeholders.

Timing (initiation, appropriate intervals, actualization), communication, documentation (emergency and care plans, advance directives, discussion protocols), and age-appropriate participation of children and adolescents are transversal aspects pertaining to the whole process.
Conclusion The developed pACP program exhibits a modular design ensuring a structured step-by-step approach as well as a personalized process aimed at meeting the highly individual needs of the child and the family.

\section{OP45 PEDIATRICIANS' EXPERIENCES AND ATTITUDES REGARDING ADVANCE CARE PLANNING}

1J Fahner* , ${ }^{2}$ Rietjens, ${ }^{2} \mathrm{~A}$ van der Heide, ${ }^{1} \mathrm{~J}$ van Delden, ${ }^{1} \mathrm{M}$ Kars. 'University Medical Center Utrecht, Utrecht, Netherlands; ${ }^{2}$ Erasmus MC, Rotterdam, Netherlands

\subsection{6/spcare-2019-ACPICONGRESSABS.45}

Background Advance Care Planning (ACP) enables individuals together with their relatives and health care professionals to discover, discuss and document their values, preferences and goals for care.

Objective To evaluate the involvement of pediatricians taking care of children with life-limiting conditions in ACP.

Methods All pediatricians from six Dutch pediatric hospitals completed a survey about experiences with ACP in their most recent case of a deceased child.

Results Of the 207 participating pediatricians (response 36\%), 168 completed the questionnaire (81\%), of which $86 \%$ described a case. Of these children, 53\% died before the age of 5 years. ACP conversations always took place with parents, mostly about diagnosis, life expectancy, goals of care, fears and worries and code status. In 23\%, ACP conversations occurred with children (age: range 2.2-17.3 years, median 11.5 years), discussing mostly joy of life, hope, diagnosis and fears and worries. 94\% of pediatricians were satisfied with their conversations skills. The occurrence rate of ACP conversations was indicated as insufficient by 49\%. Pediatricians stated in $60 \%$ that ACP conversations have to result in a documented code status. $37 \%$ said ACP conversations intend mainly to provide information to families. Reported barriers to ACP conversations were mostly parent-related, while facilitators concerned continuity of care and a multidisciplinary approach.

Conclusion Pediatricians reported to have ACP conversations mainly with parents with a focus on medical issues. Insight in the perspective of the child is limited. Education on the holistic approach of ACP and on involvement of children in ACP is needed.

\section{OP46 TALKING ABOUT LIFE AND DEATH - USING FILMS IN INTERCULTURAL PALLIATIVE CARE}

G Boland*. Pharos, Utrecht, Netherlands

\subsection{6/spcare-2019-ACPICONGRESSABS.46}

Background The number of first generation migrants needing care in the final phase of life is growing. However, they make little use of care facilities and support, while they do need it. Care providers feel insufficiently capable to provide good care to this group.

Method Based on research by Roukayya Oueslati (LUMC, publication pending) the Pharos short films 'Conversations about life and death' show situations from the last phase of life of a patient with a migration background and their immediate family members. The films are available in four 
languages at https://www.eventure-online.com/eventure/www. pharos.nl/ingesprek

The films show multiple perspectives and therefore every family member, including the patient can identify. Watching the films in a migrant gathering or information meeting, in a family setting, or possibly together with a care provider, provides a good opening for a conversation about the needs, fears, and wishes of a patient. The films can be viewed as a whole, or in fragments (of just a few minutes), e.g. the fragment about disclosure or about pain relief.

Results We see that the films are conversation starters for both migrants and care providers. People are informed about supportive care and realize they can make choices.

Conclusions Pharos wants these films to be seen by many more people and 'spreads the word'. We would love to show the films at the congress, provide translation in English on the spot, and discuss their usefulness with the public.

\section{OP47 EXPERIENCES, KNOWLEDGE AND ATTITUDES OF INFORMAL CAREGIVERS REGARDING ADVANCE CARE PLANNING. A SYSTEMATIC REVIEW AND META SYNTHESIS OF QUALITATIVE STUDIES}

${ }^{1} \mathrm{~K}$ Silies*, ${ }^{2} \mathrm{R}$ Schnakenberg, ${ }^{3} \mathrm{H}$ Langner, 'S Köpke. 'University of Luebeck, Luebeck, Germany; ${ }^{2}$ Carl von Ossietzky University Oldenburg, Oldenburg, Germany; ${ }^{3}$ Martin-LutherUniversity Halle-Wittenberg, Halle (Saale), Germany

\subsection{6/spcare-2019-ACPICONGRESSABS.47}

Background Advance Care Planning (ACP) is a communication process about a person's preferences for treatment and care in case of physical or mental deterioration, when the person is unable to express these wishes. Trained health professionals act as facilitators and relatives may be involved. The aim of our review is to explore the experiences and attitudes of informal caregivers, and their knowledge regarding ACP.

Methods A systematic literature search was conducted (participants: informal caregivers, intervention: advance care planning; databases: MEDLINE, PsycINFO, CINAHL, Cochrane Library). Eligible studies were assessed by two independent reviewers. Quality appraisal was conducted using the Critical Appraisal Skills Programme (CASP) checklists. Thematic synthesis was applied for qualitative studies. Results from quantitative studies were associated to the meta categories of the thematic synthesis.

Results 41 studies met the inclusion criteria, of which 37 qualitative studies were included in the thematic synthesis. Major themes found were: "ACP-structures", "Roles and Relationships", "Perceptions of ACP", "Caregivers' Knowledge", "Attitudes". Barriers to and facilitators for ACP from the viewpoint of caregivers were described following the structure of the major themes. The importance of caregivers' role perceptions and the mutual influence of ACP and family relationships were highlighted.

Conclusion It is widely accepted, that ACP interventions have to take caregivers' points of view into account. Our review provides a rich description of caregivers' experiences, knowledge, attitudes, and needs regarding ACP. The results will support the development of patient- and family-centred ACP interventions and of instruments that measure effects of these interventions in caregivers.

\section{OP48 \\ PLANNING AHEAD WITH HEALTHCARE: PROXIES' NEEDS AND EXPERTS' RECOMMENDATIONS TO SUPPORT ADVANCE CARE PLANNING IN SWITZERLAND}

${ }^{1} \mathrm{~F}$ Bosisio*, ${ }^{2} \mathrm{~K}$ Karzig-Roduner, ${ }^{2} \mathrm{D}$ Drewniak, ${ }^{1} \mathrm{R}$ Jox, ${ }^{2} \mathrm{~T}$ Krones. ${ }^{1}$ Lausanne University Hospital, Lausanne, Switzerland; ' ZZurich university hospital, Zurich, Switzerland

\subsection{6/spcare-2019-ACPICONGRESSABS.48}

Background When there is no advance care planning (ACP), relatives feel uncomfortable and ambivalent when deciding on behalf of someone who has lost decision-making capacity. The aim of this study was to understand proxies' needs and gather experts' views on how to improve ACP in Switzerland.

Methods We conducted 20 interviews with proxies and four with experts in the three linguistic regions of Switzerland.

Results Half of the proxies were not familiar with ACP and spoke about living wills, testaments, and financial and organizational challenges of daily care. Only four people had the opportunity to advance decisions about healthcare with their kin when $\mathrm{s} / \mathrm{he}$ was diagnosed with a neurocognitive disease. Most interviewees became proxies by the circumstances and did not discuss their role further with the patient or other relatives. For most people, ACP was made difficult by caregivers not being explicit about disease progression and potential complications and proxies' role in future decision-making. When patients were very sick but still competent, professionals tended to exclude proxies albeit decisions had huge impact not only on the patient but also on their families. Communication and coordination with professionals and money are major concerns for most interviewees, in particular parents of disabled children. Experts' views are consistent with interviewees' experiences.

Conclusions Recommendations to improve ACP in Switzerland include increasing awareness in both professionals and the public, improving communication and coordination between professionals, patients and their proxies, better supporting relatives in their most urgent needs, and broaching ACP when discussing ongoing care plans.

\section{OP49 WELLBEING OF FAMILY CARERS OF PEOPLE WHO DIED OF CANCER: PRELIMINARY RESULTS OF THE ACTION ADVANCED CARE PLANNING (ACP) TRIAL}

${ }^{1}$ I Vandenbogaerde*, ${ }^{1} \mathrm{~A}$ de Vleminck, ${ }^{1} \mathrm{~J}$ Cohen, ${ }^{1} \mathrm{MN}$ Verkissen, ${ }^{2} \mathrm{~L}$ Lapeire, ${ }^{3} \mathrm{~F}$ Ingravallo, ${ }^{4} \mathrm{~S}$ Payne, ${ }^{5} \mathrm{~A}$ Wilcock, ${ }^{6} \mathrm{~J}$ Seymour, ${ }^{7} \mathrm{MC}$ Kars, ${ }^{8} \mathrm{U}$ Lunder, ${ }^{9} \mathrm{CA}$ Christensen, ${ }^{9} \mathrm{M}$ Grønvold, ${ }^{10} \mathrm{JAC}$ Rietjens, ${ }^{10} \mathrm{~A}$ van der Heide, ${ }^{1} \mathrm{~L}$ Deliens. 'Vrije Universiteit Brussel, Brussel, Belgium; ${ }^{2}$ Ghent University, Ghent, Belgium; ${ }^{3}$ University of Bologna, Bologna, Italy; ${ }^{4}$ Lancaster University, Lancaster, UK; ${ }^{5}$ Nottingham University Hospitals NHS Trust, Nottingham, UK; ${ }^{6}$ University of Nottingham, Nottingham, UK; ${ }^{7}$ University Medical Center Utrecht, Utrecht, Netherlands; ${ }^{8}$ University Clinic for Respiratory and Allergic Diseases, Golnik, Slovenia; ${ }^{9}$ University of Copenhagen, Copenhagen, Denmark; ${ }^{10}$ Erasmus MC, Rotterdam, Netherlands

\subsection{6/spcare-2019-ACPICONGRESSABS.49}

Background Previous studies showed that family carers (FCs) who engaged in formal ACP had fewer adverse outcomes in wellbeing compared with FCs who did not. The ACTION trial is the first multicentre randomized controlled trial of ACP in six European countries. This study will report on the effect of ACP on the wellbeing of bereaved FCs.

Methods 451 questionnaires were sent to bereaved FCs 3 months after the patient participating in the trial had died; 163 were returned (response rate: 36.1\%; $\mathrm{N}$ control= 93, $\mathrm{N}$ 